Banko Jànăḱkarị, V̇ol.9,No.2

Бо0к Keview

\title{
Introduction to Forestry
}

Publisher: Vikash Publishing House Pvt. Ltd., India Year: 1998

Pages: 262

Price: IRs 135

There has always remained a constraint of reading materials particularly in the technical subjects such as forestry in the libraries of the third world countries. Nepal is not an exception to it. There could be no argument that the limitation of reading materials limits the standard of education for a given country. Students at the Institute of Forestry at Pokhara and at Hetauda have felt a greater need of text as well as reference books. And, forestry which is not a single subject, rather is the aggregation of various applied sciences, there could be no single book dealing with the forestry subjects for beginners. At such circumstances,

introductory book on forestry is always felt needed by the students to save their time from searching a vast literature

Dr. M. B. Shrivastava of the Department of Forestry, the Papua New Guinea University of Technology, who has almost thirty years of experience at various capacities in the field of forestry, has done a commendable job of writing a book entitled Introduction to Forestry. The book that covers the broad spectrum of forestry and includes silviculture, mensuration, forest survey and inventory,

management, utilisation, protection, tree improvement,

wood technology, social forestry, forest policy and law, forestry research and future trends in forestry, etc. seems to serve not only the students at the college level, but is of

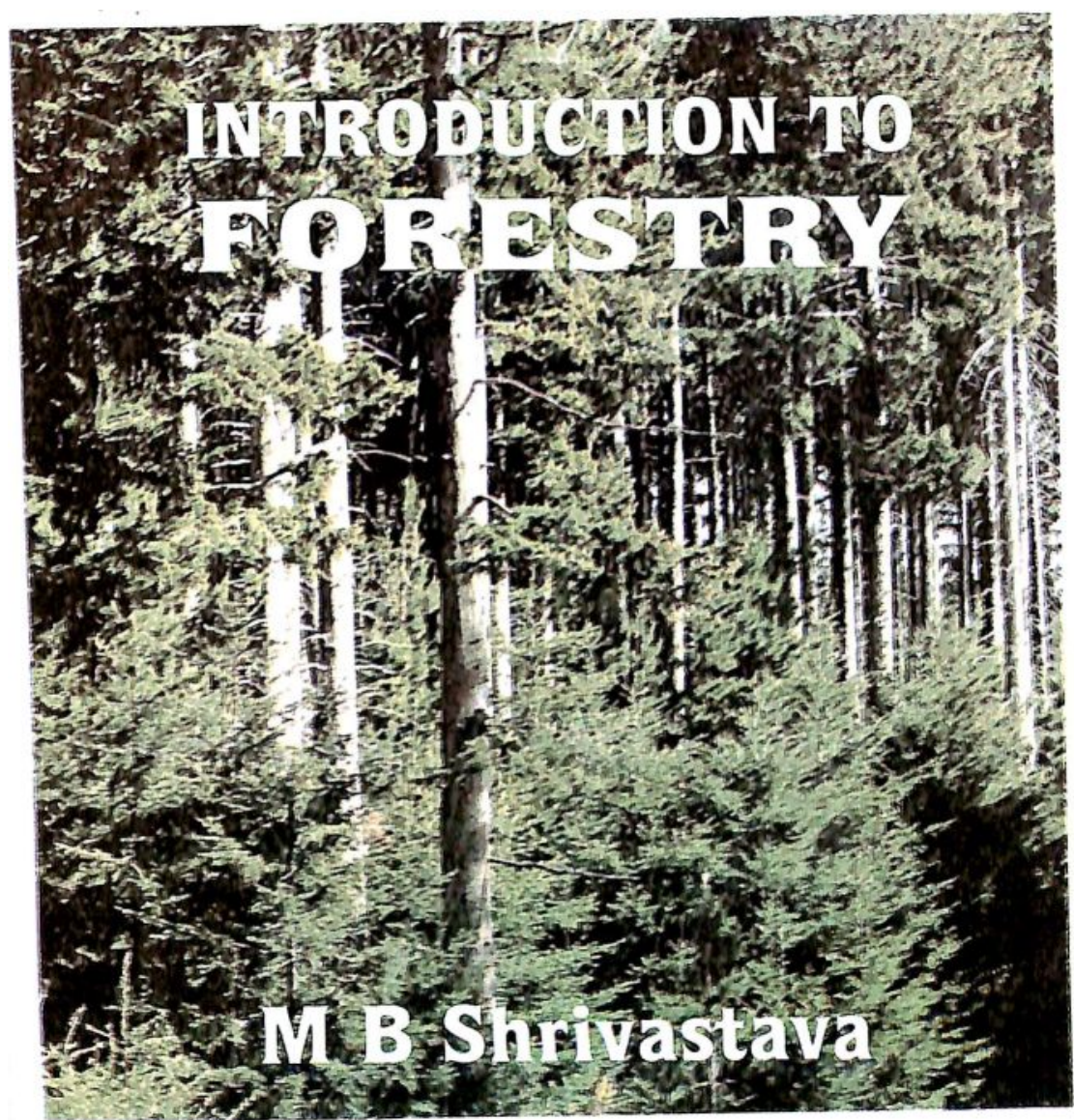

reference value to the practitioners

management. The subject which has drawn attention of the forestry managers in the third world

Distribution of forests types depends on the distribution and characteristics of climate types. In this context, the author has, wisely started with three chapters of his book with the climate of the world thereby linking it with the world vegetation types in the fourth chapter. Forests of the Indian subcontinent, though countries, and in Nepal it has remained in the top priority.

Sushim Ranjan Baral Ph.D.

Department of Forest Research and Survey 